\title{
Türkiye'deki Kitle Fonlama Web Sitelerinin Kullanılabilirlik ve Görsel Estetik Kavramları Bağlamında Görsel İletişim Tasarımı Değerlendirmesi
}

\author{
Behiç Alp Aytekin (Dr. Öğr. Üyesi) \\ Aydın Adnan Menderes Üniversitesi İletişim Fakültesi \\ alpaytekin@adu.edu.tr \\ Orcid: 0000-0001-9121-6445
}

Başvuru Tarihi: 07.12.2018

Yayına Kabul Tarihi: 18.02.2019

Yayınlanma Tarihi: 22.07.2019

DOI: 10.17680/erciyesiletisim.493680

Aytekin, B. A.. (2019). Türkiye'deki Kitle Fonlama Web Sitelerinin Kullanılabilirlik ve Görsel Estetik Kavramları Bağlamında Görsel İletişim Tasarımı Değerlendirmesi. Erciyes İletişim Dergisi, 6 (2), 1291-1308. DOI: 10.17680/erciyesiletisim.493680

Öz

Kitle fonlama ekosistemini; girişimciler, melek yatırımcılar, sponsorlar, kitle fonlama web siteleri, teknoparklar, hobiciler ve çevrimiçi teknoloji takipçileri arasında şekillenen bir üretim-iletişim-tüketim ağı yapısı olarak tanımlamak mümkündür. Çok sayıda paydaşın aynı etkileşim kurgusu dahilinde etkilenmesi söz konusu olduğu için, ekosistemin doğal olarak demokratik bir iletişim ve etkileşim ortamı yarattığı düşünülmektedir. Ekosistem sayesinde; girişimciler herhangi bir etkin sermayenin yönlendirmesine maruz kalmadan, projelerini üretim ve dağıtım düzeyine, kurumsal bir ölçeğe sahip bir marka değerine ulaştırabilmeleri mümkün olmaktadır. Böylelikle oldukça demokratik ve açık bir üretim döngüsü ortamı yaratılmaktadır. Bu yapısal özellikler bağlamında, kitle fonlama projelerinin bütçesel anlamda kaynaklanması için ilgili paydaşlara sunulduğu ve bu paydaşlar ile etkileşimli bir iletişim ortamının yaratıldığı web siteleri de özel bir önem kazanmaktadır. Bu nedenle, Türkiye'de varlık gösteren kitle fonlama web siteleri (buluşum, crowdfon, fongogo ve arıkovanı) sistem kullanılabilirlik ölçeğinden (System Usability Scale) adapte edilen web kullanılabilirlik ölçeği (Web Usability Scale) ile kullanıcı etkileşimi ve kullanılabilirlik düzeyinde ölçümlenmekte ve çalışma özelinde yaratılan tasarım değerlendirme şablonu (TDŞ) ile görsel iletişim tasarımı özellikleri üzerinden değerlendirilmektedir $(n=10)$. Böylelikle kitle fonlama projelerinin ilgili paydaşlara sunulabildiği tek kanal olan bu iletişim köprülerinin, üzerlerine düşen etkileşim sorumluluğunu ne ölçüde yerine getirebildikleri, kullanılabilirlik fonksiyonu ile görsel iletişim tasarımı standartları bağlamı ilk kez bir araya getirilerek tartışmaya sunulmaktadır.

Anahtar Kelimeler: Etkileşim Tasarımı, Kamusal Alan, Kitle Fonlama Ekosistemi, Kullanıcı Deneyimi, Kullanılabilirlik, Paylaşım Ekonomisi, Sistem Kullanılabilirlik Ölçeği, Tasarım Değerlendirme Şablonu, Web Kullanılabilirlik Ölçeği. 


\title{
Visual Communication Design Evaluation of the Crowdfunding Websites in Turkey in the Context of Usability And Visual Aesthetic Concepts
}

\author{
Behiç Alp Aytekin (Asst. Prof. Dr.) \\ Aydın Adnan Menderes University Faculty of Communication \\ alpaytekin@adu.edu.tr \\ Orcid: 0000-0001-9121-6445
}

Date Received: 07.12.2018

Date Accepted: 18.02.2019

Date Published: 22.07.2019

DOI: $10.17680 /$ erciyesiletisim. 493680

\begin{abstract}
It is possible to define crowdfunding ecosystem as a production - communication - consumption network structure that is shaped between entrepreneurs, angel investors, sponsors, crowdfunding websites, technoparks, hobbyists and online technology followers. Since many stakeholders are affected by the same interaction, the ecosystem is thought to naturally create a democratic environment of communication and interaction. Thanks to the ecosystem; entrepreneurs are able to deliver their projects to the level of production, distribution and to a brand value with an institutional scale, without being subject to the orientation of any effective capital. Thus, democratic and open production cycle environment is created. In the context of these structural features, the websites have a special importance where the crowdfunding projects are presented to the relevant stakeholders and an interactive communication environment with these stakeholders are created. Therefore, the presence of showing audiences funding websites in Turkey (bulusum, crowdfon, fongogo and arıkovanı) are measured at the level of user interaction and usability with the web usability scale (Web Usability Scale) where adapted from the system usability scale (System Usability Scale) and visual communication design properties are evaluated $(n=10)$ with design evaluation template (DET) which created especially for this research. Thus, the extent to which these communication bridges, which are the only channels in which crowdfunding projects can be presented to the relevant stakeholders, are able to fulfill their responsibility for interaction, the context of usability function and visual communication design standards are put together for the first time.
\end{abstract}

Keywords: Crowdfunding Ecosystem, Design Evaluation Template, Interaction Design, Public Sphere, Sharing Economy, System Usability Scale, User Experience, Usability, Web Usability Scale. 


\section{Giriş}

En bilinen kitle fonlama platformlarından biri olarak varlığını sürdüren kickstarter. com üzerinden kurulan şirketler ve oluşan iş hacmi hakkında gerçekleștirilen bir araştırmada (Mollick, 2016), sitenin yaklaşık 5,3 milyar dolarlık bir ekonominin oluşmasına olanak sağladığı ve web sitesi üzerinden toplanan fonlarla, 2016 yılı itibari ile kurulan 8 bin 800 şirketin yüzde 82'sinin halen faaliyetlerine devam ettiği belirlenmiştir (Kuzuloğlu, 2016). Mollick (2016) araștırmasında; Kickstarter sistemi üzerinden en az bin dolar toplayan 65 bin 326 proje sahibi ile çevrim içi anketler gerçekleştirmiştir. Bu projelerin çoğunun 7 ila 10 arası fon destekçisi ile de aynı yöntemi uygulayarak görüşmüştür. Elde ettiği bulgulara göre, kickstarter kampanyası ile fonlanan projelerin yüzde 37'si, projelerini geliştirip, piyasaya sunma olanağı bulmaktadır. Fonlanan projelerin yüzde 19'unun da fonlanan projelerinin ardından yeni iş olanaklarına ulaştıkları görülmektedir. Elde edilen verilerden de görülebileceği gibi, gönüllülük esasına dayalı destek sağlanan bir sistemde, paydaşların doğru formülasyonla bir araya gelmesi ile yeni fikir, ürün ve hizmetlerin dayatma gösteren bir sermaye grubunun etkisi ve baskısı altında kalmadan birer kamusal markaya dönüşmeleri ve kendi değer döngülerini yaratmaları mümkündür. Kickstarter platformunun varlığı ve dünya genelinde yakaladığı etkileşim başarısı da bu konunun önemli bir tartışma alanı olarak varlık göstermesi için yeterli görülmektedir.

Türkiye özelinde Mollick'in (2016) ele aldığı gibi geniş bir örneklem dahilinde yürütülmüş bir araştırma henüz yürütülmemiştir. Türkiye Bilimsel ve Teknolojik Araştırmalar Kurumu [TÜBİTAK] sosyal bilimler veri tabanında, kitle fonlama anahtar kelimesi ile arama gerçekleştirildiğinde, karşınıza sadece iki sonuç çıkmaktadır: $\mathrm{Bu}$ sonuçlardan ilki, 2017 yılında yayınlanmış olan, kitle fonlama ekonomisi üzerinden gelir vergisinin düzenlenmesi ile ilgili bir kanun teklifi üzerine bir araștırmadır (Atay, 2017). İkincisi ise 2016 yılında yayınlanmış olan, seyirci ve film ilişkisi bağlamında, kitle fonlama ekosisteminin film projelerinin fonlanması konusunda oynadığı rolü inceleyen bir makale şeklindedir (Kırel ve Aktaş, 2016). Yüksek Öğretim Kurumu [YÖK] Ulusal Tez Merkezi'nde ise henüz tamamlanmış ve veri tabanına eklenmiş bir tez çalışmasına rastlanmamıştır. Konu hakkında yayınlanmış Türkçe kitap, çeviri kitap ve bildiri yayınları ise taranmamıştır.

Böyle bir bağlam ve yaklaşım biçimi üzerinden, çalışma dahilinde Türkiye'de varlık gösteren çevrimiçi sitelerin birer iletişim kanalı olarak etkileşim başarısı ortaya konulmaya çalışılacaktır. Bu noktada çalışma iki ana araştırma sorusunu gündeme getirmektedir: Kullanılabilirlik ve görsel estetik unsurlarının web sitesi kullanıcı deneyiminin algılanması adına birlikte çalışılmasının gerekliliği ve bu iki kavramın etkileşiminin web kullanıcıları düzeyinde nasıl bir sonuç yarattığı soruları araştırmanın yöntem kurgusu dahilinde yanıtlanmaya çalışılacaktır.

\subsection{Bir İletişim ve Etkileşim Kanalı Olarak Kitle Fonlamanın Gücü}

Yegen $(2015,93)$ kitle fonlama kavramının gelişen internet teknolojileri ile birlikte kullanıcılar arasında popülerleşen bir kavram olduğunu ifade etmektedir. Hemer $(2011,1)$ ise aslında kitle fonlamanın etkileşim özüne benzer yapılanmaların çok daha eski bir yardımlaşma modeline dayandığını söylemektedir: Mozart ve Beethoven besteledikleri kompozisyonlarını, konserlere ve yayınlara dönüştürürken, dinleyicilerinden aldıkları abonelik avans bedellerinden faydalanmıştır. Çok daha yakın tarihlerden bir örnek ise, İngiliz rock grubu 
Marillion'ın, Amerika turnesini internetten duyurarak hayranlarından topladığı 60 bin dolar ile fonlamasıdır. Günümüz teknolojik olanaklarının dönüştürdüğü son şekli ile kitle fonlama sistemine odaklanmadan önce, girişimci ve fonlayıcı paydaşları bir araya getiren web sitelerinin, nasıl bir iletişim ve etkileşim ortamı sağladıklarına bakmak yerinde olacaktır.

Kitle fonlama ekosistemi özelinde yaratılan ortak mekan uzamının, antik Yunan'daki politika, din ve ticaret özelinde her türlü tartışmanın yürütülebildiği ve böylelikle topluluk haberleşmeağının canlı tutulabildiği agoralara benzer bir şekilde yapılandığı görülmektedir. Aynı antik Yunan kentlerinde olduğu gibi, kitle fonlama agoralarında da ilgili ticaret ve fikir endüstrisinin gelişebilmesi için bu konular dahilinde yapılanan paydaş toplulukların, kitle fonlama web sitelerinin etkileşimlerine yakın durdukları gözlemlenmektedir.

Antik Yunan'da da iş hacmini genişletmek isteyenlerin, agora ve limanların etraflarına yerleştikleri ve bu sayede kentin kalbinin attığı merkeze daha kolay erişebildikleri bilinmektedir (Ylmaz, 2015). Rheingold (1993) da bu yapılanmayı destekler bir ifade ile toplulukların çeşitli amaç ve iş birlikleri doğrultusunda interneti toplanma alanı olarak kullandığını ve bu durumun yeni agoralar yarattığını söylemektedir.

Kitle fonlama web sitelerinin diğer bir mekansal etkileşim özelliğinin de hakim üretim endüstrisi güçlerini rahatsız edecek boyutlarda başarılı projelerin, serbest ve işbirlikçi bir sermaye birlikteliği ile fonlandığı, yeni birer kamusal alan (Habermas, 2018) olarak çalışması görülmektedir. Budak, "kamusal alanın belirli bir fiziksel coğrafyayı ve bu coğrafyanın insanlarının ilgi sınırlarını aşarak, küresel bir ölçeğe yayıldığını", böylelikle "yeni medyanın, klasik mekan anlayışı dışında herkese açık olan ortak bir mekana erişimdeki kolaylıkla ilintili olarak kamusal alan olarak değerlendirilebildiğini" ifade etmektedir (Budak, 2016, 515). Böylelikle, ele alınan yaklaşım dahilinde, yeni agoralar üzerinden kamusal alan ile bağlantı noktasını kuvvetlendirmektedir.

Topbaş ve Doğan da $(2016,125)$ bu yaklaşımı destekleyecek șekilde; "internetin ve sosyal medyanın sağladığı olanaklarla güçlenen bireyin, özgür iradesini kullanarak, toplumsal ve siyasal alana daha fazla katılma ve müzakereci demokratik sistemin gelişmesine katkı sağlayacak özellikte" bir yapı benimsediğini ifade etmektedir. Rheingold'a (1993) ise internet; açık erişim ve gönüllü katılımın desteklendiği, kamuoyunun tartışmaya katılanlar tarafından oluşturulduğu, ilgili gündem ve yönelimin de belirlenmesi ile kamusal alan kavramının gerekliliklerinin yerine getirildiğini belirtmektedir. Her ne kadar internetin sağladığı etkileșim olanaklarının yeni bir kamusal alan yaratma yeteneğine çeşitli karşıt görüşler bildiren düşünürler olsa da (Dahlgren ve Olsson, 2007; Schalken, 1998) kitlesel fonlama ekosisteminin bir araya getirmeyi başardığı paydaşlar ve gerçekleştirilen araştırmaların da bulguladığı şekilde, elde edilen fikri ve ekonomik düzeydeki yenilikçi başarı, kitle fonlamaya ait çevrim içi yapıların kamusal alan yaratma konusunda başarılı olduğunu düşündürmektedir.

Her iki bağlamda da ortak etkileşim paydasının demokrasi kavramından kuvvet aldığı düșünülmektedir. Demokrasi kavramına etimolojik kökeni üzerinden bakacak olursak, "halkın iktidarı" anlamına geldiği görülmektedir. Ural'ın (1999) da ifade ettiği gibi bu kavram, günümüz toplumlarında birbirinden farklı anlamlar kazanmakta ve birbirinden farklı uygulamaları niteler hale gelmektedir. 
Kitlesel fonlama siteleri üzerinden bakıldığında, "halkın iktidarı" olarak mesele edilen demokrasi kavramı; hakim sermaye ve üretim endüstrisinin çarklarına karşı, kolektif çaba ve sermayenin ürünü olan fikri çıktıların, kendilerine üretim ve pazar payı bulabilmelerini sağlayan çevrim içi mekan olgusuna yani kitlesel fonlama web sitelerine denk düşmektedir. Bu bağlamda, süre giden tartışmayı destekleyecek şekilde, Topbaş ve Doğan'ın (2016, 143-144) ifadelerine bakmak gereklidir:

\begin{abstract}
Son olarak kesinlikle şunun altını çizmekgerekmektedir ki, günümüzde internet ve sosyal medya, iktidar, egemen güç ilişkileri ve ticari ilişki ağlarına karşı vatandaşta isyan ve umut ağları olușturarak özgür bir kamusal alanı yaratma misyonu bulunmaktadır. Ancak sosyal medyanın gerçek anlamda bu misyonu yerine getirmesi devlet erkinin baskısı ve buyruklarından, sermaye egemenliğinden ve kar güdüsünden bağımsız, interaktif, vatandaşların özgür, açık görülebilir, kolektif ve herkesin rahatlıkla girebileceği bir alan olmasından geçmektedir. İşte o zaman, internetin ve sosyal medyanın var olan yapısını değil potansiyel yapısını gerçek anlamda ortaya koyabilir, siber uzamda yeni agoralar yaratabiliriz. Çünkü siber uzamda oluşturulacak yeni agoralar ve katılımcı demokratik bir kamusal alan, ilke olarak, sadece keyfilik, baskı ve bürokratik hiyerarşileriyle, devlet egemenliğine değil, aynı zamanda sermaye egemenliğine, ticarileşme ve metalaşmaya karşı kurulan, kurulması gereken bir alandır.
\end{abstract}

Topbaş ve Doğan'ın (2016) önerdiği yapı üzerinden konuya üretim-iletişim-tüketim çerçevesinden baktığımız zaman, yeni agoralar ve demokratik bir kamusal alandan bahsetmenin yolunun sermaye egemenliği, ticarileşme ve metalaşmaya karşı kurulması gereken bir alandan geçtiğini bize göstermekte ve bu çalışma dahilinde öne sürülen, kitle fonlama web sitelerinin özellik olarak bu yapıyı sağladığı ve uluslararası düzeyde yapının etkileşim olanakları bağlamında başarıya ulaştığı tartışmasını desteklemektedir.

\title{
1.2. Kitle Fonlama Ekosistemi Özelinde "Paylaşım Ekonomisi"
}

Bilgi teknolojilerindeki gelişmeler, kullanıcı merkezli üretilen içeriklerin çoğaldığı, paylaşım ve iş birliğine dayalı çevrim içi yapıların gelişmesine de olanak tanımıştır (Kaplan ve Haenlein, 2010). Bu yapının örnekleri olarak; açık kaynak yazılımların kütüphane olarak barındığı Github, iş birliğine dayanarak genişleyen çevrim içi bir ansiklopedi olan Wikipedia ve kitle fonlama servisi olarak işlev gören Kickstarter platformlarından bahsetmek mümkündür. Bahsi geçen bu platformlar, teknolojik bir fenomen olarak anılan paylaşım ekonomisi yapısının içine dahildir ve her biri bu yapı dahilinde farklı etkileşim özellikleri ile varlık gösteren benzer birer araç olarak ele alınmaktadır (Hamari ve diğerleri, 2015, 2048). Hamari ve arkadaşları (2015, 2048), paylaşım ekonomisi fenomeninin birçok teknolojik gelişmeyi kapsadığını, internetin sayesinde erişim sağlanan birçok bilgi teknolojisi nimeti ile hem fiziksel hem de fiziksel olmayan ürün ve hizmetlerin paylaşımını basitleştirdiğini ifade etmektedir.

Gerçekleşen bu gelişmeler ile paylaşım kavramı da yapısal olarak büyük bir değişim geçirmiştir: Kavram, genel anlamıyla, durum (status), güncelleme (update), link veya fotoğraflar bağlamında bir bilginin değiş tokuşuna referans verecek şekilde güncellenmiştir (Kaplan ve Haenlein, 2010). E-ticaret temelli bilgi teknolojisi yapılanmasının da gelişmesi neticesinde aynı kavram, ürün ve servislerin paylaşımı olarak da işlev görmeye başlamıştır (Galbreth ve diğerleri, 2012). Paylaşım kavramı; durum, bilgi (facebook, instagram vb.) veya e-ticaret ürününün değiş-tokuşunu (hepsiburada, gittigidiyor vb.) kapsayacak şekilde var olmanın yanı sıra; hizmet tasarımı ürünleri (trivago, uber vb.), dijital ürünlerin dağıtımı (spotify, fizy vb.) ve 
bilginin servis edilmesi (wikipedia, ekşi sözlük vb.) olarak da işlev gördügüu alanı genişletmiştir (Nov ve diğerleri, 2010).

Çalışmanın ele aldığı bakış açısı üzerinden ise, paylaşım kavramının kitle fonlama ekosistemi adına ayrı bir yeri ve önemi bulunmaktadır. Üretim-iletişim-tüketim kavramları üzerinde, girişimcilerin, melek yatırımcıları ile buluştukları; fikir, ürün ve vaatlerini paylaşıp, karşılığında paylaşılan bütçeye işbirlikçi bir etkileşim dahilinde eriştikleri bir sistemden söz etmek mümkündür. Böylelikle paylaşılan şey, sadece bir fikir ve ürün odaklı proje olmaktan öte, paydaşların tümünü aynı beklenti ve vaat bağlamında bir arada tutan bir çeşit hayal olarak da gözlemlenebilir. Böylelikle Hamari ve arkadaşlarının (2015) tanımladıkları paylaşım ekonomisi; kitle fonlama ekosistemi bağlamında bir vaat ve ortak kader ekonomisine de dönüşmektedir. Fikri sermayesini ortaya koyan girişimci ekip ile bu paylaşıma inanan ve üretim bütçesini oluşturmak için sermayesini koyarak destekleyen işbirlikçi tüm paydaşlar, aynı etkileşimi kurgulayan ortak aktörler olarak, paylaşım ekonomisi kavramına yeni bir yaklaşım getirmektedir.

Kitle fonlama kavramina, ekonomi perspektifinden bakmakta da yara görülmektedir: Bu yönelim özelinde; Mollick $(2014,2)$ kitle fonlamanın mikrofinans ve kitle kaynaklama olmak üzere, iki farklı kavram seti üzerinden esinlenerek meydana gelen bir yapı olduğunu ifade etmektedir. Yanı sıra, bu kavramlar bileşiğinin, fon arttırma/biriktirme gibi kendine has bir eylem çağrısı ile bu odakta özelleşmiş web sitelerini kullanarak yeni bir paylaşım modeli ortaya koyduğunu eklemektedir. Schwienbacher ve Larralde'nin (2010) kitle fonlama ile ilgili tanımı da Mollick'i destekler niteliktedir: kitle fonlama "özel amaçları doğrultusunda hareket eden girişimci ekipleri, ihtiyaçları olan finansal kaynağı sağlayabilmeleri adına, bağış ya da ödül temelli bir yaklaşımla desteklemek adına, internet üzerinden yapılan açık bir çağrıdır."

Söz konusu edilen şey, işbirlikçi ortak bir sermaye ve üretim hayali olunca, çok daha fazla kitlesel destek elde edebilmenin yolu da paydaşlarınız ile bir araya geldiğiniz etkileşim ortamının başarısı ile doğru orantılı olarak ölçülebilmektedir. Bu çevrim içi mekan uzamında iki ayaklı bir paylaşım stratejisi söz konusudur. İlk etapta, girişimci ekibin, fikri çıktısını ilgili paydaşlara iyi pazarlayabilmesi için gerekli olan tanıtıcı bileşenler yer almaktadır. İkinci etapta ise ekiplerin entelektüel sermayesini ifade edecekleri ortamın etkileşim tasarımı prensiplerine göre doğru çalışması ve karşılıklı iletişimi üst düzeyde tutacak görsel iletişim tasarımı becerilerini taşıyabilmesi gerekliliği yer almaktadır. Çalışma bu iki ayak bağlamında, ikinci odak olan ilgili etkileşim mekanının kullanılabilirlik fonksiyonu kadar, görsel iletişim tasarımı becerilerine ve bunun etkilerine yönelmektedir.

\section{Yöntem}

Yöntem olarak orijinal bir metodolojik yaklaşım dahilinde iki aşamalı bir yapı kurgulanmıştır. İlk fazda, Türkiye'de varlık gösteren dört kitle fonlama web sitesi (buluşum, crowdfon, fongogo ve arıkovanı), sistem kullanılabilirlik ölçeğinden (SUS) (Brooke, 1996) uyarlanan web kullanılabilirlik ölçeği (WUS) (Meiret, 2009) ile puanlanmaktadır.

İkinci fazda, bu ölçekten elde edilen veri, Hamari ve arkadaşlarının (2015) çalışmasındanveSauro'nun (2016) “Measuring TheVisual Appeal ofWebsites” başlıklı 
çalışmasında, tasarımı ölçümleyebilmek adına referans verdiği araştırmalardan (Hassenzahl, 2004; Karvonen ve diğerleri, 2000; Kim ve diğerleri, 2003; Lavie ve Tractinsky, 2004; Lindgaard ve diğerleri, 2006; Tuch ve diğerleri, 2012) esinlenerek planlanan, tasarım değerlendirme şablonu (TDŞ) ile gözden geçirilmekte ve görsel iletişim tasarımı prensipleri bağlamında incelenmektedir.

Lindgaard ve arkadaşlarının (2006) gerçekleştirdiği çalışmada, kullanıcıların bir web sitesinin görsel görünümünün nasıl olduğuna 50 milisaniye içinde karar verdikleri bulgulanmıştır. Sauro (2016) bir göz kırpma süresinin bile 250 milisaniye kadar bir zaman aldığını ifade etmekte ve eğer bir anlığına bile olsa kullanıcı web sitesinin çekicilik unsurunun düşük olduğuna karar veriyorsa, ilerleyen bir noktada da bu kararının aynı şekilde devam ettiğini söylemektedir. Sitenin görsel başarısına dair, 50 milisaniye gibi bir karar verme süreci, neredeyse bilinçaltı düzeyde alınan bir karar gibi görünmektedir. Bu durum da bize, otomatik bir reflekse dönüşen bu karar anını etkileyebilmek için kullanıcı deneyimi ve görsel estetik arasında; kullanılabilirlik ve tasarım bağlamında iyi bir denge kurulması gerektiğini göstermektedir.

\subsection{Web Kullanılabilirlik Ölçeği}

SUS, 1996 yılında duyurulup, kullanılmaya başlanılmasından bu yana, 1300'ün üzerinde araştırmada ölçek olarak yer almış, bu nedenle bir endüstri standardı olarak kabul görmüş ve güvenilirliği de çeşitli araştırmalar ile sınanmış (Kadirhan ve diğerleri, 2015), hızlı, kolay kullanılabilir ve kolay adapte edilebilir bir kullanılabilirlik ölçeği olarak literatürde yerine almaktadır.

SUS bu etkilerin ölçümlenebilmesi adına 5 veya 7 dereceli olarak uygulanabilen, likert tipi bir ölçek olarak ortaya çıkmıştır. Az sayıda örneklem grupları ile sonuç alınması mümkün olduğundan, ölçeğin kolay uygulanması ve hemen sonuç alınabilmesi avantajı olarak görülmektedir (Sauro, 2016). Sistem yerine web sitesi veya başka bir ifadenin gelmesi; ölçeğin çalışma prensibini ve ortaya çıkan sonuçları etkilememekte, bu nedenle hızlı ve kolay bir şekilde yeni bir araștırma evrenine, kullanılabilirlik ölçümlemesi bağlamında adapte edilebilmektedir.

SUS ile kullanılabilirlik ve öğrenilebilirlik faktörlerine bakılabilmektedir (Sauro, 2016). Kadirhan ve arkadaşları (2015) gerçekleştirdikleri güvenilirlik çalışmasında; kullanılabilirlik faktörünün güvenilirliğini oldukça yüksek olarak tespit ederken, öğrenilebilirlik faktörünün ise düşük bir değerde, ancak kabul edilebilir seviyelerde yer aldığı bulgulamıştır. Temel olarak 10 sorudan oluşan ölçeğin uygulanması neticesinde 0 ile 100 arası bir değer elde edilmektedir. Bu değer, yüzdelik bir değer değil, birer puan değeridir. Bu doğrultuda, ölçek için 68 puan eşik değeri olarak kabul edilmektedir. 68 puanın üzerinde bir skor alan sistem veya web sitesinin, kullanılabilirlik bağlamında ortalamanın üstü olduğu ifade edilebilmekte; 68 puanın altı ise ortalamanın altı olarak kabul edilerek, ilgili referanslara göre sonuçlar okunabilmektedir (Sauro, 2016).

Bu çalışma kapsamında, Aydın Adnan Menderes Üniversitesi, İletişim Fakültesi'nde yer alan 10 öğretim elemanından, bahsi geçen 4 web sitesini değerlendirmeleri talep edilmiştir. Bu değerlendirmeyi gerçekleștirebilmeleri için, verilen yanıtlara göre SUS skorunu otomatik olarak hesaplayan ve ücretsiz erişim sağlanabilen usabilityscale. com web sitesinin sağladığı altyapı kullanılmıştır. Elde edilen bulgular ve skorlar üzerinden, sitelerin kullanılabilirlik durumları değerlendirmeye alınmıştır. 


\subsection{Tasarım Değerlendirme Şablonu}

Estetik, güzellik, görsel algı gibi kavram setleri üzerinden literatüre baktığımızda araştırmaların bu soyut kavramları ölçümlemek için kendi soru setleri ve ölçeklerini geliştirdikleri ve çeşitli yapılar kurmaya çalıştıkları gözlemlenmektedir (Sauro, 2016). Bu bağlamda, yanlış bulguların elde edilmesine firsat vermemek adına, yalnızca psikolojik onay ve geçerlilik süreçlerinden geçebilen çalışma ve ölçeklere yoğunlaşarak ilerlemekte fayda görülmektedir. Bu yönelim ile öncelikle, tasarım değerlendirme şablonuna adaptasyon için bilimsel geçerlilik standardına sahip olan, Lavie ve Tractinsky (2004) tarafından geliştirilen anket ve ölçeklendirme çalışmasına bakılmıştır. Çalışmada yürütülen dört farklı saha neticesinde, aşağıda yer alan 5 temel ifadenin ölçümlenmesinin, web sitelerinin kullanılabilirlik ve estetik değerleri arasındaki ilişkiye dair güvenilir sonuçları ortaya çıkartabildiği bulgulanmıştır.

- Estetik (Aesthetic)

- Simetrik (Symmetrical)

- Hoş (Pleasant)

- Organize (Organized)

- Temiz (Clean)

Köklerini klasik ve dışavurumcu estetik yargllardan alan bu kavram setleri, kullanıcılar tarafından, 5’li likert tipi bir ölçek dahilinde değerlendirilmektedir. $\mathrm{Bu}$ 5 temel ifadenin ilk 3 kavramı yapısal olarak klasik estetik ölçeğinden gelmektedir. Böylelikle, kullanılabilirlik değişkenlerinin etkisinde kalmadan, sadece estetik değerlendirmenin bu kavramlar üzerinden daha rahat okunabileceği ifade edilmektedir (Tuch ve diğerleri, 2012).

Lavie ve Tracktinsky'nin (2004) çalıșmasından da yönelim alarak geliştirilen farklı görsel estetik ölçekleri bulunmakta ve bu ölçekler arasında yoğunluklu olarak Moshagen ve Thielsch'in $(2010,2013)$ geliştirdiği "Visual Aesthetics of Websites Inventory" (VisAWI) ve bu ölçeğin kısa formu kullanılmaktadır. Moshagen ve Thielsch $(2013,3)$ Lavie ve Tracktinsky'nin (2004) klasik estetik ve dişa vurumcu görsel estetik bağlamında iki faktöre bakarken; kendi ölçeklerinin bu çalışmayı tamamlayacak şekilde, basitlik, çeşitlilik, renklilik ve zanaat kalitesi kavramlarına da odaklandığını ve kuvvetini bu detaylı faktör yapısından aldığını ifade etmektedir. Ancak Lavie ve Tracktinsky'nin (2004) ölçeği bahsi geçen VisAWI'den daha az faktörlü olmasına rağmen, hem ölçeğin geçerlilik ve güvenilirlik bulguları hem de ölçeğin sorguladığı 5 kavram setinin sadece kullanılabilirlik ve estetik odağında iki faktöre sonuç vermesi, bu araştırma adına ölçeğin tercih edilmesine neden olmuştur. Estetik ve kullanılabilirlik sonuçlarını ayrı ayrı bulgulayabilmek, araştırmanın bu iki kavram seti arasındaki etkileşim ilişkisini anlayabilmek adına önemli bir tercih olarak görsel estetik yaklaşımı bağlamındaki yöntem yaklaşımının bütününü oluşturmaktadır.

Konunun bulgulanan başka bir yönü de kullanıcıların görsel anlamda çekici sitelere, çekici olmayanlara nazaran daha çok güvendiklerinin saptanması yönündedir. Çalışmalar aynı zamanda, kullanılabilirlik ve güven kavramları arasındaki ilişkinlik düzeyi ve etkinin de yüksek düzeyde olduğunu göstermektedir (Sauro, 2016). Bu bağlamda, kullanılabilir olanın aynı zamanda güzel olduğuna yönelik bir bağlantı kurmak mümkün görünmektedir. Kesin olarak ifade etmek söz konusu edilmese de kullanıcıların daha kullanılabilir siteleri güzel bulduğuna dair bir fikir ortaya çıkmaktadır. 
Avrupa'da gerçekleștirilen bir araştırmanın bulguları da bu yargıyı destekler niteliktedir (Tuch ve diğerleri, 2012): Araștırma esnasında bir dizi kullanılabilirlik testi, klik takibi, senaryo sonrası anket ve sistem kullanılabilirlik ölçeği gibi ölçümlemeye başvurulmuştur. Web sitelerinin görsel güzelliklerini ölçümlemek için bahsi geçen Lavie ve Tracktinsky'nin (2004) kavram seti ile birlikte, Hassenzahl'in (2004) hazsal ölçeğinden faydalanılmıştır. Önemli bir sonuç olarak, çekici olarak kabul gören web sitelerinin kullanılabilirlik puanlarını yükseltmediği ancak bunun yerine daha kullanılabilir olan web sitelerinin görsel güzellik boyutunda ölçeklerdeki puanları yükselttiği bulgulanmıştır. Özetle, "güzel olan kullanılabilir değil, kullanılabilir olan güzeldir" (Tuch ve diğerleri, 2012). Bu bulgu ile kullanılabilirlik ve görsel güzellik arasındaki ilişkinlik durumunun hangi yönde çalıştığı da açıklığa kavuşmaktadır.

Gerçekleştirilen bu çalışmaların güvenilirliği doğrultusunda TDŞ hem kullanılabilirlik ilişkinliğini anlamak hem de estetik değerlendirme yapabilmek adına, Lavie ve Tractinsky (2004) önerdiği şekli ile kullanılmış ve 4 kitle fonlama sitesi için aynı örneklem grubu siteleri puanlamıştır. Her bir ifade için, en az 1, en çok 5 ve ortalama değerin yer aldığı bir skala kullanılmıştır.

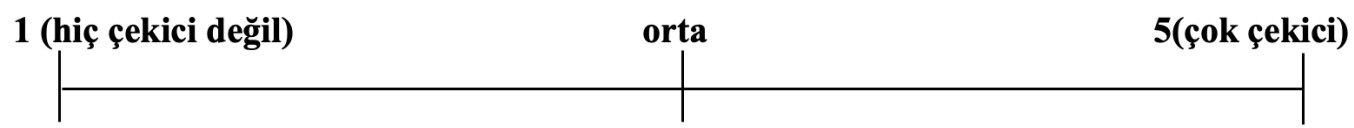

Şekil 1: Tasarım değerlendirme şablonu puanlama skalası

1 hiç çekici değil ve 5 çok çekici değerlerini ifade etmektedir. 5 ifade için de kullanıcılardan elde edilen puanlar toplanmış ve 25 tam puan (5 ifade için $5 \times 5=25$ puan) üzerinden değerlendirilerek, skaladan elde edilen verilerin ortalamaları hesaplanmıştır.

\subsection{Kapsam Dışı Bırakılanlar}

Çalıșma Türkiye'de varlık gösteren çevrimiçi sitelerin etkileşim başarına odaklanmaktadır. $\mathrm{Bu}$ bağlamda, kullanılabilirlik ve görsel estetik unsurlarının web sitesi kullanıcı deneyiminin algılanması adına etkileşim etkisine ve ilişkisine bakmaktadır. $\mathrm{Bu}$ ilişkinin iyi anlaşılabilmesi için, yaklaşım dahilinde gündeme gelebilecek diğer unsurların çalışmanın kapsamı dışında bırakılması gerekmektedir. Bu nedenle araştırmanın odağında yer alan gözlem ve ölçüm gerçekleştirilirken, iki temel konu kapsam dișı olarak bırakılmıștır:

Birinci konu olarak, projelerini fonlatmak için bu sistemlere dahil olan yürütücü ve proje ekiplerinin, görsel iletişim tasarımı becerileri kapsam dışı bırakılmaktadır. Projeyi yürüten ve kamuoyuna sunan ekiplerin, projelerini nasıl tanıttıkları, marka oluşturdukları ve ilgili görsel iletişim tasarımı bileşenleri ile projelerine talep yaratacak dinamikleri çalıştırdıkları elbette oldukça önemlidir. Ancak aynı araştırma dahilinde hem varlık gösterecekleri ekosistemin iletişim kanalı olarak ele aldığımız çevrimiçi platformu incelemek ve değerlendirmek hem de projelerin görsel tasarımları açısından nasıl ele alındıklarını incelemek, odaklanılan konunun dağılmasına yol açacak șekilde geniș bir bakıșa neden olacaktır.

Kapsam dışı bırakılan ikinci konu ise çalışılacak olan web sitelerinin teknik açıdan çoklu platform uyumluluğu ve desteğidir. Bu konu tamamen kullanılabilirlik 
temelli teknik bir konudur. Yanı sıra, mobil cihazlar için akışkan tasarım, görsel estetik yoğunluğundan ziyade; hız, teknoloji ve cihazlar-ekranlar arası uyumluluk prensipleri bağlamında tasarım çözümleri gerektiren bir konudur. Böyle teknik gereklilikler, bu çalışmada ele alınan temel görsel estetik prensiplerinin çok daha farklı bir odaktan, teknik açıdan etkileşim temelinde ele alınmasını gerektirir. Bu çalışmada ele alınan ilişki elbette ki böyle bir yaklaşım ile mobil uyumluluk bağlamında da gerçekleştirilebilir ve yeni bir araştırma olarak sunulabilir. Ancak bu çalışmada platformlar arası uyumluluğu da göz önünde bulundurmak, araştırmanın kullanılabilirlik odağında yoğunlaşmasına neden olacaktır ve bu çalışma için istenilen kavram dengesini bozacaktır.

Ele alınan nedenler gözetilerek ve çalışmanın ilgili kapsamı düşünülerek, araştırma dahilinde belirli bir yönelimle ve yöntemle yol alınmıştır ve bahsi geçen iki odak kapsam dışı bırakılmıştır.

\section{Bulgular ve Değerlendirme}

Türkiye'deki kitle fonlama web sitelerinin kullanılabilirlik ve görsel estetik performanslarını ölçümlemek için yapılan metodolojik kurgu dahilinde, 10 katılımcı ile gerçekleştirilen WUS ve TDŞ çalışmalarının puanları aşağıdaki şekilde oluşmuştur:

Tablo 1: Web Sitelerinin Web Kullanılabilirlik Ölçeği ve Tasarım Değerlendirme Şablonu Puanları

\begin{tabular}{|l|c|c|}
\hline Web Sitesi & WUS Puanı & TDŞ Puanı \\
\hline arıkovanı & 77 & 23 \\
\hline fongogo & 75 & 22 \\
\hline crowdfon & 72 & 20 \\
\hline buluşum & 66 & 16 \\
\hline
\end{tabular}

Puan tablosuna bakıldığı zaman, WUS puanı yüksek olan web sitelerinin, TDŞ üzerinden tanımlanan skalada sonucunda da görsel iletişim tasarımı performanslarına yüksek puanlar aldıkları görülmektedir. Bu durum, Tuch ve arkadaşlarının (2012) sonuç olarak bulguladıkları, kullanılabilirlik puanları yüksek olan web sitelerinin güzellik boyutunda da ölçeklerdeki puanları yükselttiği sonucunu doğrulanmaktadır. Tekrar hatırlamak gerekirse: "Güzel olan kullanılabilir değil, kullanılabilir olan güzeldir" (Tuch ve diğerleri, 2012).

Çalışma neticesinde, en yüksek WUS ve TDŞ performansına arıkovanı web sitesi ulaşmıştır (http://wwww.arikovani.com). Web sitesinin, TDŞ üzerinden sunulan skalada, simetrik ve organize ifadelerinde birer puan kaybetmiş olduğu bulgulanmaktadır. Web sitesinin puan kaybettiği bu alanlar, araştırmanın yöntem bölümünde irdelendiği șekli ile kullanılabilirlik ve görsel estetik değerleri ile ilișkili alanlardan birer puan olacak şekilde gözlemlenmiştir. Bu durum da çalışmanın ele aldığı, iletişim köprülerinin etkileşim tasarımı dahilinde sağlıklı kurulabilmesi adına gerekli olan süreçleri vurgulamaktadır. 


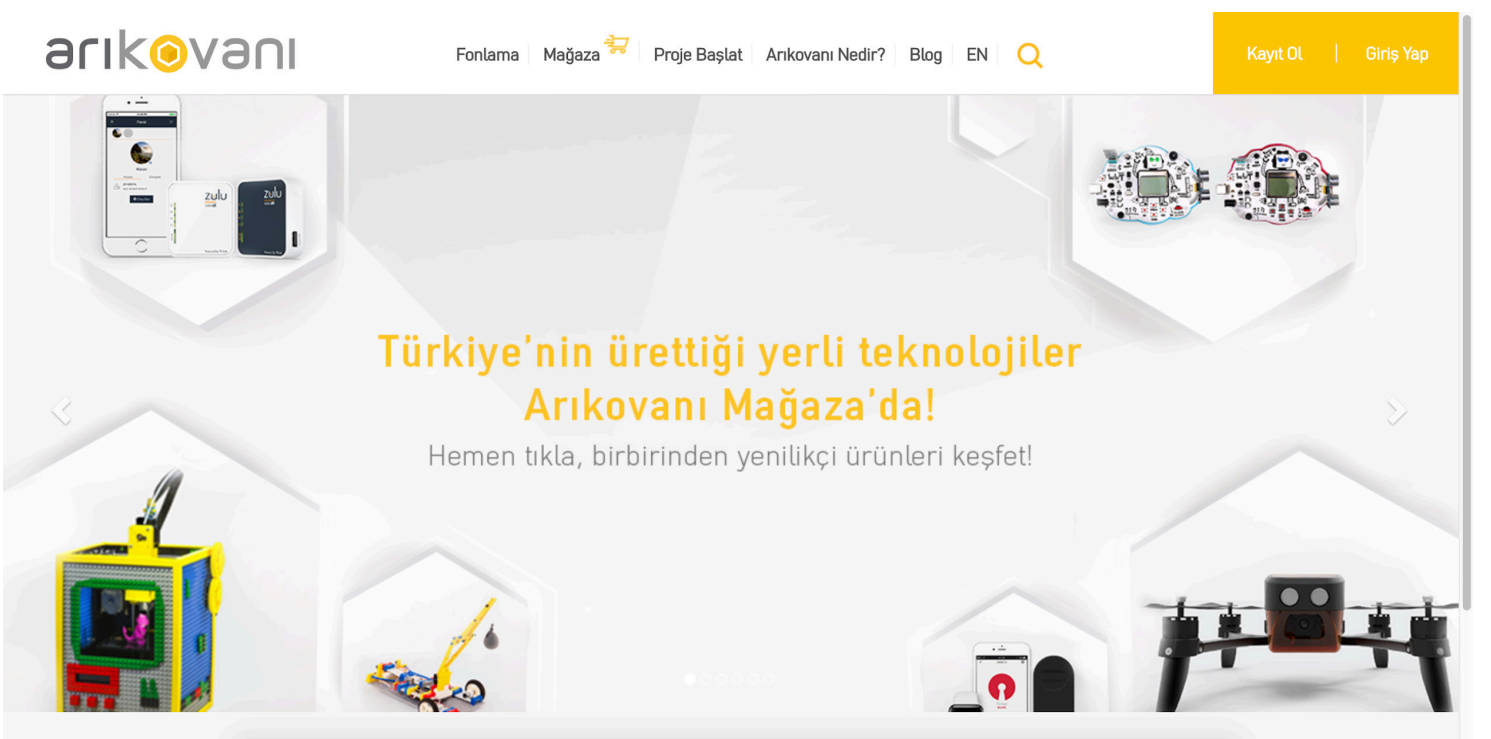

Şekil 2: Web kullanılabilirlik ölçeği ve tasarım değerlendirme şablonu puanı en yüksek olan site (http://www.arikovani.com)

Sitenin puan kaybettiği simetrik ifadesi, Lavie ve Tractinsky (2004) tarafindan geliştirilen ölçeklendirme özelinde, klasik estetik kavram setinden beslenen bir kavram olarak, sitenin görsel iletişim tasarımı becerisi üzerindeki performansını etkilerken; diğer ifade olan organize ise yine aynı ölçekte (2004), etkisi vurgulanan kullanılabilirlik fonksiyonu anlamında, sitenin ufak da olsa bir problem yaşadığını göstermektedir.

Problem yaşanılan alanları detaylı olarak ele alacak olursak; web sitesi dahilinde projelerin fonlandığı alanın, simetri ifadesi üzerinde daha yüksek puan elde eden diğer sitelerden farklı olarak, 4'lü değil, 3 sütunlu bir proje gruplama tasarımına sahip olduğu görülmektedir. $\mathrm{Bu}$ nedenle kullanıcıların görsel algı boyutunda, simetriyi tam olarak yakalayamadıkları düşünülmektedir. Elbette ki 3 sütunlu yapı da simetriktir. Ancak 4 sütunlu tasarımlar ile karşılaștırıldığında, 4 sütunlu yapıların simetri öğesinin vurgusu adına daha etkili olduğu görülmektedir. Bu nedenle bu 3 sütunlu yapının tasarımı, kullanıcılar tarafından diğer örneklere göre bir puan eksi olarak değerlendirilmiştir.

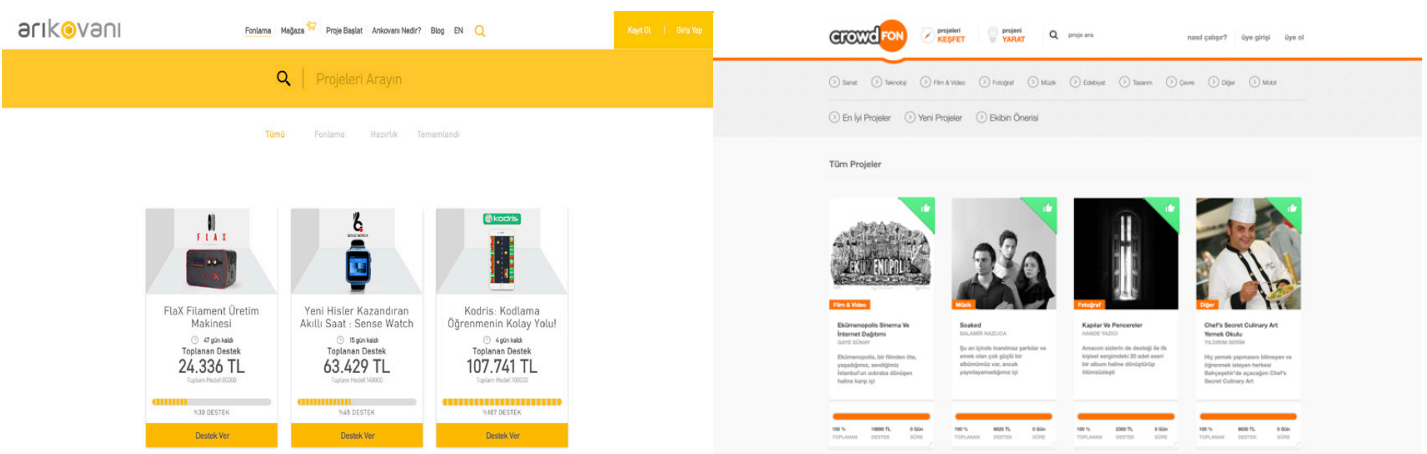

Şekil 3: Arıkovanı ile Crowdfon web sitelerinin proje sergileme yapısı farkı

Şekil 3'te de görülebileceği gibi, crowdfon web sitesi proje sergi sayfasında 4 sütunlu bir yapıya sahiptir. Bu nedenle sunulan simetrinin tasarım olarak kuvveti kullanıcılara daha etkili gelmektedir. Bu nedenle crowdfon web sitesi, genel puan sıralaması dahilinde üçüncü sırada yer alsa da simetri puanı olarak arıkovanı web sitesinden daha yüksek puan almıştır. 
Organize ifadesi üzerinde ise proje detay sayfalarında yer alan projeye ait bilgi bloklarının, görsel iletişim tasarımı bağlamında ve Gestalt Prensipleri (Graham, 2008; Interaction Design Foundation [IDF], 2015) özelinde; doğru gruplama ve görsel hiyerarşi yapısına uygun olarak düzenlenmediği görülmektedir.

arıkevanı

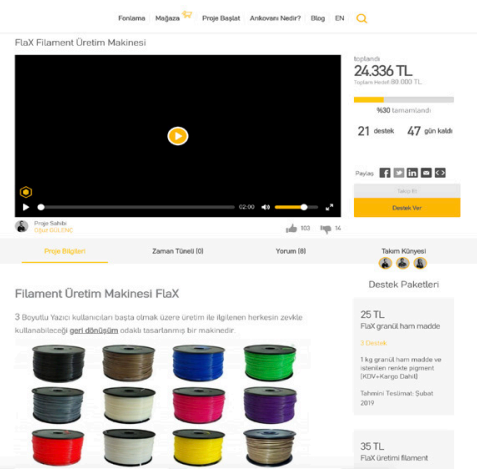

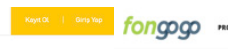

SENIOR ROBOTIK TAKIMI'NA HAYALLERI IÇIN DESTEK

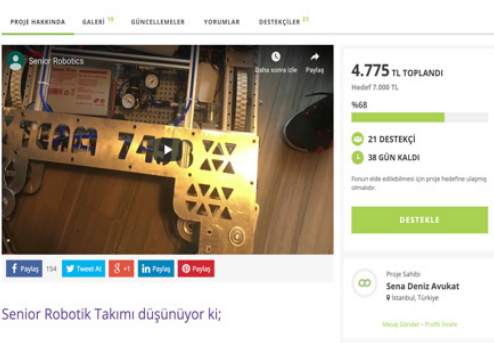

Şekil 4: Arıkovanı ve Fongogo web sitelerinin proje detay sayfaları farkı

Projeye ait destek paketleri bölümü, tasarım arka planından ayrılmaları adına dikdörtgen ve gri zeminli bloklar olarak düzenlense de destek paketleri bölümünün ilgili yeni bir başlık olarak yeterince vurgulanmaması; yanı sıra, paket türlerinin dikkati çekecek şekilde kurgulanmaması hem gruplama hem de tasarımın genelindeki hiyerarşik yeri adına bu önemli bölümün tam işlevsel çalışmasına engel olmaktadır. Ayrıca, toplam hedef, toplanan fon, destek için kalan zaman ve sosyal medya paylaşım butonlarının mesafesel yakınlığının yeniden düzenlenebileceği düşünülmektedir. Bu noktadaki ilişki gruplama adına bir zayıflık olușturmakta ve kullanıcı deneyimi için hiyerarşik bir problem yaratmaktadır.

Karşılaştırma yapmak adına şekil 4'te fongogo sitesinin proje detay sayfasında yer alan toplam hedef, toplanan fon, destek için kalan zaman bloğunun tasarım çözümüne de yer verilmiştir. Fongogo'nun tasarım çözümünün mesafesel yakınlık prensibine göre daha dikkatli kurgulandığı, böylelikle gruplama etkisinin kullanıcı adına daha iyi çalıştığı gözlemlenmektedir. Gruplamaya destek olarak kullanılan tipografik tercih birlikteliği ve leke değerlerinin ortak etkisi, renk unsuru ile birlikte, kullanıcı deneyimi adına bu içerik grubunun hiyerarşisini de ön plana çıkarmaktadır. Bu bağlamda arıkovanı web sitesi için kullanılabilirlik adına genel bir değerlendirme yaptığımızda, Gestalt Prensiplerinin anahtar elemanlarından olan mesafesel yakınlık (proximity), benzerlik (similarity), gruplama (grouping) ve hiyerarşi (hierarchy) kavramlarının kullanımına dair tasarım çözümlemelerinde tasarım problemleri bulgulanmaktadır.

Gestalt Prensiplerinin çevrimiçi arayüz tasarımları özelinde, kullanıcı deneyimi açısından nasıl doğru çalışması gerektiğine yönelik güncel araştırmalar da bu çalışmanın bakış açısını doğrulamaktadır. Bu bağlamda Bufe (2018) Gestalt Prensipleri doğru anlaşıldığı takdirde, nasıl daha iyi bir kullanıcı deneyimi yaratılabileceğinin de anlaşlabileceğini ifade etmekte; böylelikle kullanıcının dikkatini doğru yere ve içeriğe yönlendirecek daha kullanıcı dostu arayüzlerin tasarlanabileceğini vurgulamaktadır.

Görsel tasarım çözümlemeleri kaynaklı eksikliklerin web sitelerinin görsel estetik algılarını etkilediği görünse de kullanılabilirlik skorunun etkisinin, bu bölümün başında da tekrar ifade edildiği gibi, görsel estetik adına eksiklikleri giderdiği 
görünmektedir. Araştırılan bu kullanılabilirlik ve görsel estetik etkileşimin etkisi doğrultusunda, arıkovanı web sitesi eksiklerine rağmen WUS puanının etkisi ile sıralamada birinci site olmuştur. Sitenin WUS puanı ve performansının, yine sitenin en yüksek TDŞ puanına ulaşmasında da etkili olduğu düşünülmektedir.

Çalışmadan elde edilen bu sonuçlar bağlamında, araştırma sorusu olarak gündeme getirilen kullanılabilirlik ve görsel estetik unsurlarının web sitesi kullanıcı deneyiminin algılanması adına birlikte çalışılmasının gerekliliği ve bu iki kavramın etkileșiminin web kullanıcıları düzeyinde nasıl bir sonuç yarattığı sorularının yanıtları da tespit edilebilmiştir. Bu araştırmanın bulguları da Tuch ve diğerlerinin (2012) araştırmasının sonuçlarını doğrulamaktadır: Kullanıcılar açısından kullanılabilir olan, estetik açıdan da güzel olan olarak algılanmaktadır. Tamamen estetik kaygılarla, kullanılabilirliği düşünülmeden tasarlanmış bir web sitesi ise görsel açıdan tüm formüller doğru çözümlense bile güzel olarak ele alınmamaktadır.

$\mathrm{Bu}$ çalışmanın sonuçları, kullanılabilirlik ve görsellik unsurlarının web sitelerinin fonksiyonel ve estetik yapıları bağlamında nasıl çalışması gerektiğini anlamak adına önemsenmektedir. Kitle fonlama gibi web sitesi temelli sosyal aksiyonlar gündeme geldiğinde, bu ilişkiyi iyi anlamak ve kurgulamak, arzu edilen fonlama ve destek ekosistemi yaratmak ve doğru çalıştırmak adına oldukça önemli bir rol üstlenmektedir.

\section{Sonuç}

Jan Van Dijk'in Ağ Toplumu (2016) kitabında ifade ettiği şekliyle; yeni medyanın hızlı ilerleyişi, yeni bir iletişim devriminin meydana gelmesine neden olmaktadır: "Yeni medya teknolojisi devrimseldir. Ancak yeni medya araçlarının toplum üzerindeki etkisi daha çok evrimseldir ve toplumdaki eğilimleri güçlendirmektedir" (Dijk, 2016, 38). Yine Dijk'e (2016) göre; konuşmanın icadından bu yana toplumlar belirli ağ yapıları içinde örgütlenmektedir. Bu bağlamda ağ toplumu kavramı, yeni bir kavram olarak görülmemektedir. Dijk bu yaklaşımı ile sosyal ağların, insanlık kadar eski olması durumuna dikkati çekmektedir (Öztürk, 2017). Dijk; internetin insan hayatını, "güçlü ve geniş bir hiper bağ" yapısına dönüştürdügünü söylemektedir. Bu bağlamda Dijk (2016), yeni medyanın küresel güçleri olarak Microsoft, Apple, Google, Facebook, Twitter ve diğer sosyal medya şirketlerini ele almaktadır. Bu durumda, Google'ın interneti bir enformasyon aracı haline getirdiğini, Facebook'un interneti bir sosyal araca dönüştürdügünü, Apple'ın ise hepsini bir araya getirerek iletişim, eğlence ve popüler uygulamaları yeni medya araçları için taşınabilir yaptığını, Microsoft'un da interneti çevrimiçi günlük işleri halletmek için farklı bir boyutta uygulamalar serisi sunduğunu söylemektedir.

$\mathrm{Bu}$ yönelim üzerinden incelediğimiz zaman, kitle fonlama web sitelerinin de interneti dijital etkileşim dahilinde en işlevsel uygulama topluluklarından birine dönüştürmüş olduğunu tartışmak mümkündür. Daha açık bir ifade ile uygulamanın bilgisinin paylaşıldığı bir platformda, hayaller açık edilmekte ve destekçilerin maddi ve manevi katkıları ile bu teknolojik fonlama ağı, açık edilen hayallerin elle tutulur birer projeye dönüșmesine yardım etmektedir. Kapitalist ekonomi sisteminin tersine bir hareket biçimi olarak varlık gösteren bu imece ağının yarattığı ekonomik değer ve fonlanan projelerin başarılı olma yüzdeleri ele alındığında, bahsi geçen diğer yeni medya küresel güçleri kadar büyük bir etki yarattığı gözlenmektedir. $\mathrm{Bu}$ nokta itibariyle, kitle fonlama web sitelerinin merkezi etkileşim fonksiyonu 
olan, projelerin fonlanması boyutuna baktığımızda; çevrimiçi para harcamaya etki eden durumların, kültürel, sosyal, kişisel ve psikolojik boyutlarda sınıflandırıldığ görülmektedir (Rani, 2014). İcil Tuncer ve Tuncer (2016) ise bahsi geçen her bir boyutu biçimlendiren tutumların gelişmesinde deneyim ve iletişim kavramlarının büyük oranda etki ettiğini söylemektedir. Deneyim ve etkileşim kavramlarının etkisi, araştırma dahilinde tartışılan şekli ile kitle fonlama web siteleri için paylaşım ekonomisi paydasını oluşturmaktadır. Yaratılan bu payda, kullanıcılar, girișimciler ve fonlama etkileşimi dahilinde bir ekosisteme dönüșmekte; ekosistemin başarısı da web sitesi etkileşiminin kullanılabilirlik ve görsel iletişim tasarımı becerilerinin başarısı ile ölçülebilmektedir.

Z Kuşağı çocukları artık somut birer tüketiciye dönüşmüştür. Bu bağlamda bu kuşak, tüketim toplumunun en aktif bireyleri olarak görülmektedir. Bu durum kitle fonlama ekosistemiözelinde, girişim sahiplerinin bu kuşağın özelliklerini gösteren tüketicilere hitap etmesi ve bu kullanıcılar üzerinde belli etkileşim aksiyonlarını başlatabilecek düzeyde tasarımlara odaklanması gerekliliğini gündeme getirmektedir. Tuncer'in $(2016,34)$ de ifadesi ile; "ağ toplumun çocukları için yeni dünya, parmakların ucunda, göz hizasındaki ekranlardan ibarettir. Z kuşağının yüksek içerikli medya ve çoklu ekranlarla çevrili dünyası hem bir farkyaratmak isteyen hem de bilgiye nasıl ulaşacağını iyi bilen bir kuşak" yaratmaktadır. Bu yönelim doğrultusunda, kullanılabilirlik ve görsel estetik unsurlarının birlikte ölçeklenip, ölçümlenmesini öneren yeni bir metodolojik yaklaşım daha önce gündeme getirilmiştir (Aytekin, 2018). Bu araştırma ile de bu metodolojik yaklaşım önerisinin işlerliği doğrulanmaya çalışılmıştır. Tüm bu yaklaşım özelinde, kitle fonlama web sitelerinin böylesine etkileşim alışkanlıkları olan bir kullanıcı-tüketici topluluğa hitap edebilen çevrimiçi bir pazar yeri olduğu; bir başka yaklaşımla, çevrim içi mekansal uzamın sanal agoraları olduğu rahatlıkla ifade edilebilmektedir.

İlerleyen çalışmalarda bu tüketicilerin kitle fonlama paydaşları ve birer kullanıcı olarak görülmesi gerektiği düşünülmektedir. $\mathrm{Bu}$ kullanıcıların tutum ve yaklaşımlarının analiz edilebilmesi adına, nicel veriler ile birlikte nitel verilerin de derinlemesine araştırıldığı ve hatta biyometrik kullanıcı bulguları ile desteklendiğibir araştırma evreninin yaratılması ve örneklemlerin bu yaklaşım dahilinde incelenmesi önerilmektedir. Bu ikili metodolojik araştırma yaklaşımın ölçümleme avantajlarının, benzeri bir bakış açısı doğrultusunda, detaylı çevrimiçi etkileşim analizleri için yol gösterici bir yöntem olarak benimseneceği düşünülmektedir. Yanı sıra çalışma dahilinde kapsam dışı olarak bırakılan iki temel odak da ilerleyen çalışmalarda, bu araştırmadan elde edilen bulguların desteği ile çalışılabilecek yeni odaklar olarak görülmektedir. $\mathrm{Bu}$ bağlamda, projelerini fonlatmak için kamuoyuna arz eden ekiplerin, projelerini nasıl tanıttıkları, marka oluşturdukları ve ilgili görsel iletişim tasarımı bileşenleri ile projelerine talep yaratacak dinamikleri nasıl çalıştırdıkları gündeme alınması oldukça kıymetli bir içerik olarak değerlendirilmektedir. Aynı şekilde, kitle fonlama web sitelerinin teknik açıdan çoklu platform uyumluluğu ve desteği de yüksek oranda mobil cihazların kullanıldığı bir internet evreninde kullanılabilirlik ve görsel estetik bağlamındaki ilişkileri anlamak ve çözümlemek adına oldukça kıymetli bir araştırma alanı olarak görülmektedir.

Tüm fikri ve destekçi grupların ortak aksiyon alabildiği bir etkileşim modelini, tek yönlü bir araştırma stratejisi ile sadece kullanılabilirlik fonksiyonları doğrultusunda ölçümlemek yeterli değildir. Konunun görsel estetik taraflarını 
incelemek, projeye destek ol veya projeyi fonla butonları ile etkileşime geçmeden önce, kullanıcının hangi görsel iletişim tasarımı motivasyonları ile güdülendiğini de anlamayı gerektirmektedir. Bu yaklașım doğrultusunda, araştırma ile bulgulanan kullanılabilirlik ve görsel estetik ilişkisinin etkileşim dinamiğini anlamanın, hem ilerleyen çalışmaları kurgulamak ve yönlendirmek adına hem de bu tarz içerikler için aksiyon alan tasarımcı ve diğer uygulayıcılara yönelim sunabilmek adına önemli bir temel bilgiyi oluşturduğu düşünülmektedir.

\section{Kaynakça}

Atay, H. (2017). Melek Yatırımcı Gelir Vergisi İndirimi Uygulaması ile Kitle Fonlaması Kanun Tasarısı Üzerine Bir Tartışma. Vergi Raporu Dergisi, 3, 9-19.

Aytekin, B. A. (2018). Kitle Fonlama Ekosisteminin Siyasal İletişim Rolü ve Etkileşim Deneyimi için Metodolojik Bir Önerme. Political Communication in Theory and Practice: Non-Western Approaches Proceeding Book, 1, 357-362. Aydın Adnan Menderes Üniversitesi, Türkiye. Erişim Adresi: http://akademik.adu.edu.tr/ fakulte/iletisim/webfolders/PICS2018_Proceeding_Book_YENI_small(1).pdf

Brooke, J. (1996). SUS-A Quick and Dirty Usability Scale. Usability Evaluation in Industry, 189(194), 4-7.

Budak, H. (2016). Kamusal Alanda Dönüșen Yapılar: Agoradan Sanal Uzama. Selçuk Üniversitesi Edebiyat Fakültesi Dergisi, 0(36), 507-507.

Bufe, A. (2018). The key to intuitive UX - Gestalt Principles. Erişim: 12.01.2018, Medium Ă Sitesi: https://medium.com/uxcam/the-key-to-intuitive-uxgestalt-principles-bluespace-371345b077cf

Dahlgren, P. ve Olsson, T. (2007). From public sphere to civic culture: Young citizens' internet use. Media and Public Spheres. Erişim: 11.03.2018, Springer Ağ Sitesi: https://link.springer.com/chapter/10.1057/9780230206359_16

Dijk, J. V. (2016). Ağ Toplumu. İstanbul: Kafka Yayınevi.

Galbreth, M. R., Ghosh, B. ve Shor, M. (2012). Social Sharing of Information Goods: Implications for Pricing and Profits. Marketing Science, 31(4), 603-620.

Graham, L. (2008). Gestalt theory in interactive media design. Journal of Humanities \& Social Sciences, 2(1), 1-12

Habermas, J. (2018). Kamusallığın Yapısal Dönüşümü. (15. Basım) (T. Bora ve M. Sancar, Çev.) İstanbul: İletişim Yayınları.

Hamari, J., Sjöklint, M. ve Ukkonen, A. (2015). The sharing economy: Why people participate in collaborative consumption. Journal of the Association for Information Science And Technology. 67(9), 2047-2059

Hassenzahl, M. (2004). The interplay of beauty, goodness, and usability in interactive products. Human-Computer Interaction, 19(4), 319-349.

Hemer, J. (2011). A Snapshot on Crowdfunding, Working Papers Firmes and Region. Germany: Fraunhofer ISI.

İcil Tuncer, A., Tuncer, M. U. (2016). Kişilerarası İletişimin Dijitalleşmesi: E-Forum Etkileşiminin Tüketici Davranışına Etkisi. İletişim Kuram ve Araştırma Dergisi, 42(Bahar), 322-339. 
Interaction Design Foundation. (2015). Gestalt Principles. Erişim: 15.09.2018, Interaction-design Ağ Sitesi: https://www.interaction-design.org/literature/ topics/gestalt-principles

Kadirhan, Z., Gül, A. ve Battal, A. (2015). Sistem Kullanılabilirlik Ölçeği: Geçerlik Ve Güvenirlik Çalışması. Eğitim Bilimleri ve Uygulama, 14(28), 149-167.

Kaplan, A. M. ve Haenlein, M. (2010). Users of the world, unite! The challenges and opportunities of Social Media. Business Horizons, 53(1), 59-68.

Karvonen, K., Cardholm, L. ve Karlsson, S. (2000). Cultures of trust: A cross-cultural study on the formation of trust in an electronic environment. Proceedings of the nordic workshop on secure IT systems (s. 89-100), Reykjavik: DBLP.

Kim, J., Lee, J. ve Choi, D. (2003). Designing emotionally evocative homepages: an empirical study of the quantitative relations between design factors and emotional dimensions. International Journal of Human-Computer Studies, 59(6), 899-940.

Kırel, S. ve Aktaş, S. (2016). Seyirci ve Film Üretim İlişkisinde Yeni Yaklașımlar: Kitlesel Fonlama Uygulamaları ve Türkiye'deki Deneyimler. Sinecine Sinema Araştırmaları Dergisi, 7(1), 103-137.

Kuzuloğlu, S. (2016). Kickstarter'ın İstikrarlı Ekonomisi. Erişim: 21.10.2016, Dünyahalleri Ağ Sitesi: http://www.dunyahalleri.com/

kickstarterin-istikrarli-ekonomisi

Lavie, T. ve Tractinsky, N. (2004). Assessing dimensions of perceived visual aesthetics of web sites. International Journal of Human-Computer Studies, 60(3), 269298.

Lindgaard, G., Fernandes, G., Dudek, C. ve Brown, J. (2006). Attention web designers: You have 50 milliseconds to make a good first impression! Behaviour \& Information Technology, 25(2), 115-126.

Meiret, J. O. (2009). SUS: How to Easily Grade Your Site's Usability. Erişim: 09.10.2018, Meiert Ă̆ Sitesi: https://meiert.com/en/blog/sus-how-to-grade/

Mollick, E. (2014). The dynamics of crowdfunding: An exploratory study. Journal of Business Venturing, 29(1), 1-16.

Mollick, E. R. (2016). Containing Multitudes: The Many Impacts of Kickstarter Funding. Erişim: 12.05.2018, Papers SSRN Ă̆ Sitesi: https://papers.ssrn.com/sol3/ papers.cfm?abstract_id $=2808000$

Moshagen, M. ve Thielsch, M. T. (2010). Facets of visual aesthetics. International Journal of Human-Computer Studies, 68 (10),689-709.

Moshagen, M. ve Thielsch, M. T. (2013). A short version of the visual aesthetics of websites inventory. Behaviour \& Information Technology, 32 (12), 1305-1311.

Nov, O., Naaman, M. ve Ye, C. (2010). Analysis of participation in an online photosharing community: A multidimensional perspective. Journal of the American Society for Information Science and Technology, 61(3), 555-566. 
Öztürk, Ș. (2017). Kitap Değerlendirme: Ağ Toplumu. Erişim: 15.08. 2017, Yenimedya Ağ Sitesi: https://yenimedya.wordpress.com/2017/08/09/kitapdegerlendirme-ag-toplumu/

Rani, P. (2014). Factors influencing consumer behaviour. International Journal of Current Research and Academic Review, 2(9), 52-61.

Rheingold, H. (1993). The Virtual Community. MA: Addison-Wesley Reading.

Sauro, J. (2016). Measuring Usability With The System Usability Scale (SUS). Erişim: 20.06.2018, Userfocus A $\breve{g}$ Sitesi: https://www.userfocus.co.uk/articles/ measuring-usability-with-the-SUS.html

Schalken, K. (1998). Internet As A New Public Sphere For Democracy? W. B. H. J. Van De Donk ve I. T. M., Snellen (Ed.). Public Administration in An Information Age (s. 159-175). Amsterdam: IOS Press.

Schwienbacher, A. ve Larralde, B. (2010). Crowdfunding of Small Entrepreneurial Ventures. Douglas Cumming (Ed.) Handbook of Entrepreneurial Finance. (14. Bölüm) Oxford: Oxford University Press.

Topbaş, H. ve Doğan, A. (2016). Toplumsalın Yeni Agorası Olarak Sosyal Medya: Eleştirel Yaklaşım. Gümüşhane Üniversitesi İletişim Fakültesi Elektronik Dergisi, 4(1), 124-148.

Tuch, A. N., Roth, S. P., Hornbæk, K., Opwis, K. ve Bargas-Avila, J. A. (2012). Is beautiful really usable? Toward understanding the relation between usability, aesthetics, and affect in HCI. Computers in Human Behavior, 28(5), 1596-1607.

Tuncer, M. U. (2016). Ağ Toplumunun Çocukları: Z Kuşağının Kișilerarası İletişim Becerilerinin Çok Boyutlu Analizi. Atatürk İletişim Dergisi, 10, 33-45.

Ural, H. Ş. (1999). Demokrasi Kavramı, Toplumsal Değerler Ve Birey. İlahiyat Fakültesi Dergisi, XL(40). Erişim: 15.09.2018, https://www.safakural.com/makaleler/ demokrasi-kavrami-toplumsal-degerler-ve-birey

Yegen, C. (2015). İletişim teknolojileriyle gelişen crowdsourced bir sistem olarak crowdfunding ve "FonlaBeni" örneği. E. Saka, A. Sayan ve V. Görgülü (Ed.), Yenimedya Çalışmaları III (87-111). İstanbul: Taşmektep Yayınları.

Yılmaz, K. (2015). Agora Nedir? Erişim: 8.10.2018, Arkeolojihakkindakihersey A $\breve{g}$ Sitesi: https://arkeolojihakkindahersey.blogspot.com/2015/03/agora-nedir. html 
